\title{
Esophageal stents for less invasive treatment of mediastinitis
}

\author{
Jarmil Safranek, Jan Geiger, Vladimir Vesely, Josef Vodicka, Vladislav Treska \\ Department of Surgery, Charles University, Teaching Hospital, Plzen, Czech Republic
}

Videosurgery Miniinv 2014; 9 (1): 1-5

DOI: 10.5114/wiitm.2014.40156

\begin{abstract}
Introduction: In spite of the progress in diagnosis and therapeutic options, esophageal perforation resulting in mediastinitis is a very serious condition with a high morbidity.

Aim: To evaluate the use of esophageal stents for the treatment of patients suffering from mediastinitis.

Material and methods: Retrospective (2008-2012) analysis of a group of patients requiring surgical treatment. The evaluation was focused on the cause of perforation, stent type and its parameters, the surgical method used, duration of stenting and total length of treatment.

Results: In total, 16 patients were treated by stenting. All patients were treated with the stent being placed across the defect in the esophagus. Mediastinitis was accessed and drained with the aid of a thoracotomy or thoracolaparotomy (8 cases), or using a combination of a laparotomy/laparostomy and pleural drainage (5 cases). The most basic interventions were either pleural or external cervical drainage ( 3 and 1 cases, respectively). One patient, in whom a stricture had developed at the healed perforation, was subjected to esophageal resection. Four patients died. The average period that the stent was left in situ was 53.7 days. The average period of hospitalization of those patients who survived was 53.4 days. Conclusions: Using stents in therapy neither increased survival (mortality of 25\%), nor decreased the length of therapy of patients once mediastinitis had developed. The main advantage of stenting is the preservation of the native esophagus and the reduced extent of surgical mediastinal drainage.
\end{abstract}

Key words: mediastinitis, esophageal perforation, esophageal stent.

\section{Introduction}

Anastomosis insufficiency and esophageal perforation often lead rapidly to mediastinitis, in many cases resulting in fatality (mortality of $15-75 \%$ ). The most frequent cause of this condition in patients is an endoscopic examination (50-75\% of reported perforations), and particularly endoscopic interventions [1-4]. Esophageal perforations occurring during the diagnostic esophagogastroscopy (EGDS) are reported with a frequency of about $0.05-0.1 \%$ of all EGDS [5]. The next most frequent causes of esophageal perforation and mediastinitis are spontaneous perforation, impacted food bolus, foreign bodies, esophageal corrosion (10\%), and trauma (1-3\%) [1]. Postoperative complications include anastomotic insufficiency after esophageal resection, perforation during esophagofundoplication and esophageal injury during other thoracic surgery procedures [6].

\section{Aim}

To evaluate the use of esophageal stents for the treatment of patients suffering from mediastinitis due to esophageal perforation.

\section{Material and methods}

We performed a retrospective analysis of a patient group with mediastinitis caused by an esoph-

\section{Address for correspondence}

Jarmil Safranek MD, PhD, Department of Surgery, Charles University, Teaching Hospital, Alej Svobody 80, 30460 Plzen, Czech Republic,

phone: +420 732368206, e-mail: safranek@fnplzen.cz 
ageal defect that had been treated by stenting at our department. The analysis covers a period of 5 years (2008-2012). Mediastinitis was diagnosed by endoscopic or esophagram evidence of an esophageal defect and mediastinal collection was identified by computed tomography (CT), which then requires surgical intervention. Patients included in the study group were originally treated at our department or transferred from other hospitals. None of them were subjected to primary surgical treatment outside our department. Each patient was administered broad-spectrum antibiotics and antimycotics. Patients with perforation of a malignant esophageal tumor, not indicated for primary surgical treatment, were excluded from the study. We implanted a stent manufactured by ELLA-CS, Hradec Kralove, Czech Republic. We evaluated the cause of perforation, type of stent and its parameters, the surgical techniques used, the period that the stent was left in situ and the period of hospitalization.

\section{Results}

Within the period 2008-2012, 16 patients with mediastinitis following esophageal injury were operated on. latrogenic esophageal lesion caused the mediastinitis in 8 patients. Six patients suffered from postoperative perforation ( 3 of these with anastomotic insufficiency after esophageal resection, 2 with perforation after esophagofundoplication, and 1 patient with perforation after cardiomyotomy) while there were 2 cases of perforation during EGDS. The etiology of esophageal perforation was spontaneous in 4 cases ( 2 without any obvious pathology, 1 related to hiatal hernia and 1 related to reflux esophagitis). Three cases of perforation were due to an impacted food bolus (meat, trichobezoar) and acid corrosion was the cause in 1 case.

After documented evidence of perforation or insufficiency of the esophagus, all patients were treated using surgical drainage and, in addition, by a stent implanted across the defect. The stent was introduced as soon as possible after evidence of perforation was made available, on average after a period of 1.8 days (within the range of 0-9 days) related to the presence of an endoscopy-trained surgeon at the department and the availability of an optimal stent. In 14 cases the stent was implanted under endoscopic control and in 2 cases perioperatively, without endoscopy.
The majority of chosen stents had a diameter of $20 \mathrm{~mm}$, with a proximal flare preventing dislocation. The stent is made of nitinol alloy with high corrosion resistance. It is covered by polyurethane foil. The length of the stent was within 100-150 mm. In cases where a custom made biodegradable polydioxanone stent was used, the larger diameter of $25 \mathrm{~mm}$ was preferred. The stent length was arranged in cooperation with the manufacturer.

The average period that non-biodegradable stents were left in situ in surviving patients was 53.7 days (with a range of 20-95 days). The results with respect to types of stents implanted are presented in the Table I.

The surgical approach of thoracotomy, or thoracolaparotomy, was used for draining the mediastinitis in 8 cases. Another 5 cases were drained by using the combination of laparotomy/laparostomy and pleural drainage. Pleural drainage alone was sufficient in 3 cases, external cervical drainage in one case. An acute esophagectomy was not needed in any case. It was, however, performed in one case, but already after the perforation had healed, and because of early stenosis. Four of the patients making up the group died (mortality of $25 \%$ ). The others were discharged or transferred to other departments.

\section{Discussion}

In spite of the progress in diagnosis and therapeutic options, esophageal perforation resulting in mediastinitis is a very serious condition with a high morbidity of about 20\% (range of $0-40 \%$ ) [7-10]. Therapy requires information on the site of perforation demonstrated by an esophagram or endoscopy. If these examinations do not reveal a perforation, it is useful to repeat the esophagram within a couple of hours, or to perform $\mathrm{CT}$ with an orally administered contrast agent [11]. In addition, CT contributes to the assessment of the possible extent of mediastinal involvement, revealing the emphysema, exudate and abscess of the mediastinum or pleural cavity. These factors represent the main factor in the choice of surgical techniques or type of surgery. Minnich indicates the period beyond $24 \mathrm{~h}$ of the occurrence of the defect as being significant $(p=0.02)$ in the necessity of surgical intervention [12]. Computed tomography evidence of exudate dissemination through the mediastinal pleura (non-contained perforation, $p=0.04$ ) is also a negative prognostic factor [12]. 


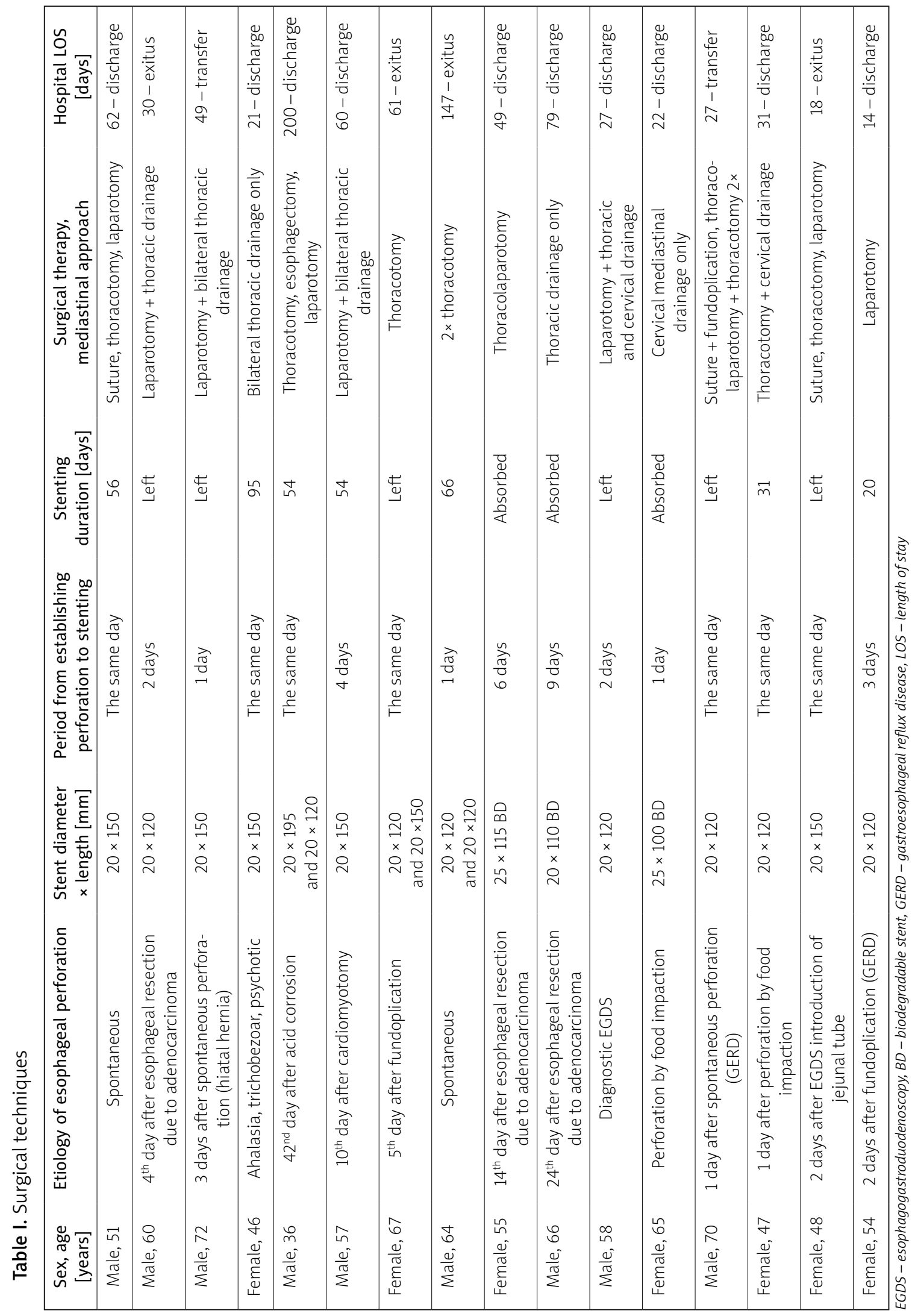




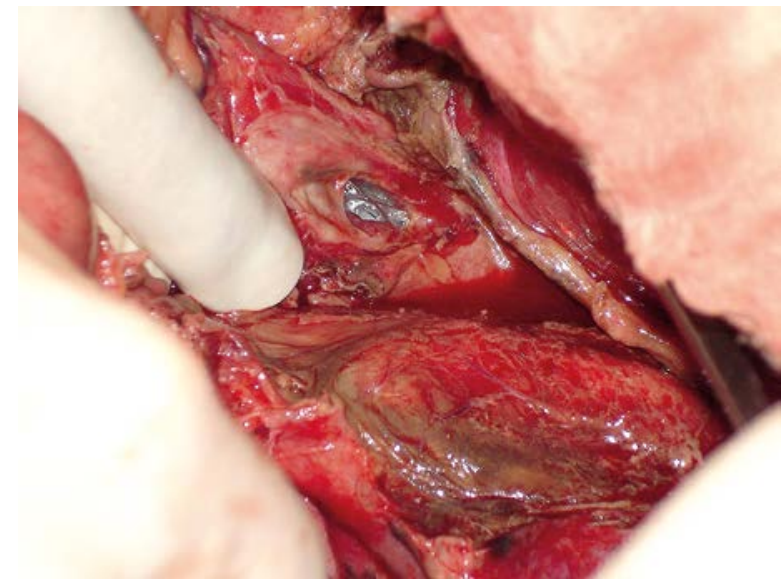

Photo 1. Intraoperatively introduced stent. Stenting was followed by esophageal suture supported by fundoplication

The treatment of mediastinitis after esophageal perforation follows four main principles: closing the perforation, drainage of the mediastinum, broad-spectrum antibiotics/antimycotics, and adequate nutrition [13]. Primary suture, better in two layers (mucosal and muscular), is recommended for closing, provided the perforation margins are suitable for suture [14]. Reinforcement of the suture with the aid of a muscle flap, pleura, pericard or fundoplication would be advantageous and is recommended [15]. In cases when the period after perforation is longer than $24 \mathrm{~h}$, many authors recommend just the drainage of the adjacent mediastinum and refer to frequent failure of the primary suture $[3,16]$. A con-

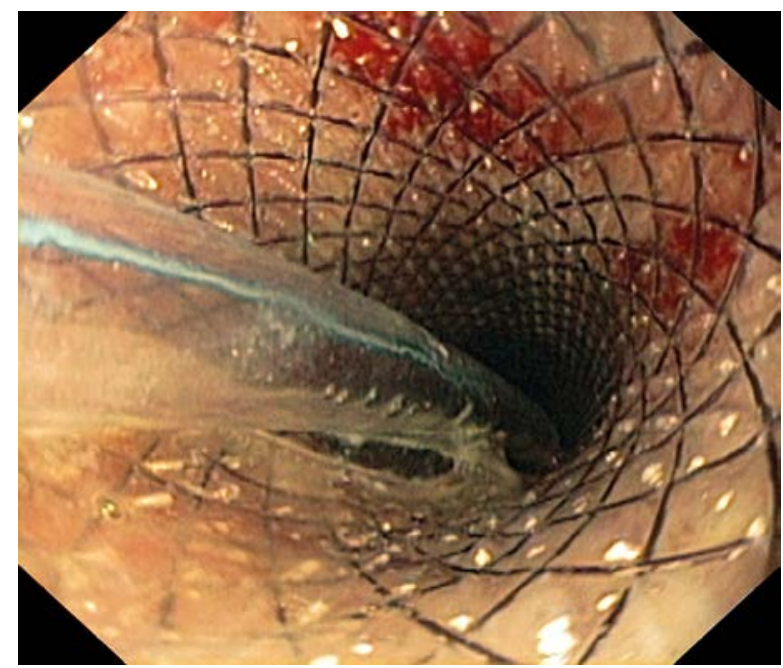

Photo 2. Endoscopic view after concurrent introduction of the stent and nasogastric tube tradictory view prefers a primary surgical suture regardless of the time elapsed since the injury [17-19]. The decision on the type of treatment required is always made on an individual basis and often results from observations made during the surgery. The need for making a wide surgical access to the area of perforation represents a drawback of the primary suture therapy. The anastomotic insufficiency after esophageal resection precludes the suturing entirely.

Stenting makes a significant contribution to current treatment (Photo 1). If we presume healing of the perforation and stent extraction, the stent type and quality of metal it is made of are less important than the need for using the stent with a covering (polyethylene or polyurethane) that should prevent leakage from the stent lumen. The design of the proximal stent flare sufficiently prevents the stent migration that occurs in up to $30 \%$ of cases in which other stents are used [20-22]. The recommended period between stent implantation and removal that is considered to be optimal is 1 month (sometimes even 2, max. 3 months). If the healing of the defect does not take place within the chosen implantation period, it is possible to implant a further stent. Stents made of biodegradable material (polydioxanone) are now available and may be applied in situations when the future extraction of the stent is uncertain.

A combined procedure consisting of concurrent stenting and suturing of the perforation (Photos 2 and 3), eventually reinforced by a flap formed by soft tissue, seems to be advantageous in cases of "uncer-

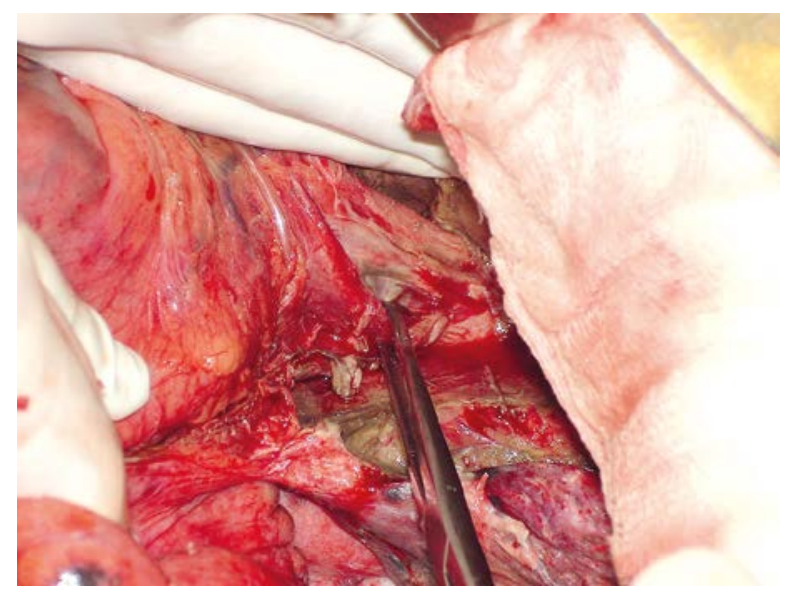

Photo 3. Spontaneous perforation of the distal esophagus, the approach from a left-sided thoracolaparotomy (about $24 \mathrm{~h}$ after the injury). The margin of the perforation is grasped by Allison forceps 
tain" primary esophageal suture. We consider the single stent implantation to be better than an immediate esophageal resection. The extent of radical surgical intervention of mediastinitis caused by perforation of the carcinoma depends on the patient's condition and the extent of malignant disease [23, 24]. Drainage of mediastinitis is related to the mediastinal level which is affected. External drainage of the upper mediastinum is possible through a cervical approach by establishing passive or flushing drainage. A majority of cases of distal esophageal perforations require an approach from a thoracotomy or thoracolaparotomy. The perforation of the abdominal part of the esophagus requires an approach from a laparotomy and mediastinal drainage through the diaphragmatic hiatus or by establishing a thoracic drainage.

\section{Conclusions}

Performance of the surgical revision of mediastinitis after esophageal perforation depends on the extent of mediastinal involvement demonstrated by CT. The surgery is aimed at closing the defect with sutures, a stent or a combination of both interventions. Nowadays, we use the stent in almost all cases of esophageal perforation. Stenting neither increases survival (mortality of $25 \%$ ) nor decreases the length of therapy once mediastinitis has developed. It facilitates the preservation of the native esophagus and limits the extent of surgical drainage. However, esophagectomy remains an essential part of the therapeutic spectrum. Its indication is made on a wholly individual basis and depends on the general health condition of the patient and on local surgical findings.

\section{References}

1. Brinster CJ, Singhal S, Lee L, et al. Evolving options in the management of esophageal perforation. Ann Thorac Surg 2004; 77: 1475-83.

2. Port JL, Kent MS, Korst RJ, et al. Thoracic esophageal perforations: a decade of experience. Ann Thorac Surg 2003; 75: 1071-4.

3. Vogel SB, Rout WR, Martin TD, Abbitt PL. Esophageal perforation in adults. Aggressive conservative treatment lowers morbidity and mortality. Ann Surg 2005; 241: 1016-23.

4. Vallböhmer D, Hölscher AH, Hölscher M, et al. Options in the management of esophageal perforation: analysis over a 12year period. Dis Esophagus 2010; 23: 185-90.

5. Mai C, Nagel M, Saeger HD. Surgical therapy of esophageal perforation. A determination of current status based on 4 personal cases and the literature. Chirurg 1997; 68: 389-94.

6. Hermann J, Kościński T, Malinger S, et al. Strangulation of the stomach and the transverse colon following laparoscopic esophageal hiatal hernia repair. Videosurgery Miniinv 2012; 7 : 311-4.

7. Griffith EA, Yap N, Poulter J, et al. Thirty-four cases of esophageal perforation: the experience of a district general hospital in the UK. Dis Esophagus 2009; 22: 616-25.

8. Jougon J, Mc Bride T, Delcambre F, et al. Primary esophageal repair for Boerhaave's syndrome whatever the free interval between perforation and treatment. Eur I Cardiothorac Surg 2004; 25: 475-9.

9. Abbas G, Schuchert MJ, Pettiford BL, et al. Contemporaneous management of esophageal perforation. Surgery 2009; 146: 749-55.

10. Gupta NM, Kaman L. Personal management of 57 consecutive patients with esophageal perforation. Am J Surg 2004; 187: 58-63.

11. Castelguidone E, Merola S, Pinto A, et al. Esophageal injuries: spectrum of multidetector row CT findings. Eur J Radiol 2006; 59: 344-8.

12. Minnich DJ, Yu P, Bryant AS, et al. Management of thoracic esophageal perforations. Eur J Cardiothorac Surg 2011; 40: 931-7.

13. Shields TW. Esophageal trauma. In: Shields TW, Licicero III J, Reed CE, Feins RH. General thoracic surgery. 7th edition. Philadelphia, Lippincott Williams \& Wilkins 2009; 2101-20.

14. Whyte RI, lannettoni MD, Orringer MB. Intrathoracic esophageal perforation: the merit of primary repair. J Thorac Cardiovasc Surg 1995; 109: 140-6.

15. Grillo HC, Wilkins EW Jr. Esophageal repair following late diagnosis of intrathoracic perforation. Ann Thorac Surg 1975; 20 : 387-99.

16. Eroglu A, Turkyilmaz A, Aydin Y, et al. Current management of esophageal perforation: 20 years experience. Dis Esophagus 2009; 22: 374-80.

17. Wright CD, Mathisen DJ, Wain JC, et al. Reinforced primary repair of thoracic esophageal perforation. Ann Thorac Surg 1995; 60: 245-9.

18. Wang N, Razzouk AJ, Safavi A, et al. Delayed primary repair of intrathoracic esophageal perforation: is it safe? J Thorac Cardiovasc Surg 1996; 111: 114-22.

19. Richardson JD. Management of esophageal perforations: the value of aggressive treatment. Am J Surg 2005; 190: 161-5.

20. Salminen P, Gullichsen R, Laine S. Use of self-expandable metal stents for the treatment of esophageal perforations and anastomotic leaks. Surg Endosc 2009; 23: 1526-30.

21. Fischer A, Thomusch O, Benz S, et al. Nonoperative treatment of 15 benign esophageal perforations with self-expandable covered metal stents. Ann Thorac Surg 2006; 81: 467-72.

22. Gelbmann CM, Ratiu NL, Rath HC, et al. Use of sef-expandable plastic stents for the treatment of esophageal perforations and symtomatic anastomotic leaks. Endoscopy 2004; 36: 695-9.

23. Morgan RA, Ellul JP, Denton ER, et al. Malignant esophageal fistulas and perforations: management with plastic-covered metallic endoprotheses. Radiology 1997; 204: 527-32.

24. Duda M, Adamcik L, Czudek S, et al. Miniinvazivní resení komplikaci v jicnové chirurgii. Slovenská Chirurgia 2010; 7: 21-4.

Received: 17.05.2013, accepted: 30.06.2013. 